\title{
The Effects of Counseling about Death and Dying on Perceptions, Preparedness, and Anxiety Regarding Death among Family Caregivers Caring for Hospice Patients: A Pilot Study
}

\author{
Yeojung Jung, R.N., M.S., Hyun-E Yeom, R.N., Ph.D.* and Na-Ri Lee, M.D. ${ }^{\dagger}$ \\ Department of Nursing, Jeonbuk National University Hospital, Jeonju, "Department of Nursing, Chungnam National University, \\ Daejeon, ${ }^{\dagger}$ Department of Hema-oncology, Jeonbuk National University Hospital, Jeonju, Korea
}

Purpose: This pilot study aimed to examine the influence of death counseling on perceptions, preparedness, and anxiety regarding death and dying among family caregivers of hospice patients. Methods: Death counseling developed based on the SPIKES model was provided to 37 family caregivers in a hospice and palliative care unit. Perceptions, preparedness, and anxiety regarding death were assessed with a self-administered structured questionnaire, and participants' scores before and after counseling were compared using the paired t-test. Results: Significant changes were found in perceptions, preparedness, and anxiety regarding death after counseling. Compared to before counseling, the scores for perceptions of death $(t=-4.90, P<0.001)$ and preparedness for death and dying $(t=-16.23, P<0.001)$ improved, while anxiety $(t=3.72, P=0.001)$ decreased after counseling. Some changes were also found in the types of support that family caregivers needed to prepare for the death of their family members in the hospice care unit. Conclusion: The findings demonstrate that death counseling could help family caregivers prepare for the death of their loved ones. Hospice and palliative care providers should play a key role in supporting family caregivers of hospice patients by developing strategies for counseling.

Key Words: Counselling, Death, Perception, Anxiety, Hospice care, Family, Caregivers
Received October 7, 2020

Revised December 22, 2020

Accepted December 30, 2020
Correspondence to

Hyun-E Yeom

ORCID:

https://orcid.org/0000-0001-6541-7526 E-mail:yeom@cnu.ac.kr

The article is a revision of the first author's master's thesis from Chungnam National University.

\section{INTRODUCTION}

\section{Background}

Hospice and palliative care refers to holistic care provided through the late stages of cancer, death, and grief for terminal cancer patients and their family members. The number of hospice and palliative care institutions is increasing in South Korea, with 86 institutions (1,407 beds) in 2020 [1]. Interest in hospice care has been on the rise since the Act on Hospice and Palliative Care and Decisions on Life-Sustaining Treatment for Patients at the End of Life was enacted in 2018. Nurses caring for hospice patients deliver multidimensional and holistic care, involving not only treatments to control patients' pain and symptoms before, during, and after death, but also emotional support to ease perceptions of death, spiritual suffering, and psychological pain of patients and the sadness and anxiety of family members [2]. According to a study of grieving family

This is an Open Access article distributed under the terms of the Creative Commons Attribution Non-Commercial License (http://creativecommons.org/licenses/by-nc/4.0/) which permits unrestricted non-commercial use, distribution, and reproduction in any medium, provided the original work is properly cited.

Copyright (c) 2021 by Korean Society for Hospice and Palliative Care 
members conducted by the National Cancer Center in 2019 [3], family members had relatively low satisfaction with informational and emotional support regarding death and the situation following death, indicating a lack of professional programs that help hospice patients and their family members prepare for death.

As a unique sociocultural characteristic of the South Korean medical system, family members have a high level of responsibility for the care of hospice patients; as a result, family caregivers repeatedly and directly observe patients' physical and psychospiritual distress and deterioration, increasing their anxiety and uncertainty regarding the meaning of life [4]. In previous studies, $38.1 \%$ of cancer patients experienced anxiety, and the anxiety experienced by family members was closely related to suicidal impulses [5]. Therefore, psychological support and care to ease the anxiety of family members taking care of hospice patients are necessary.

Individuals' attitudes and views towards death vary depending on personal life experiences, and perceptions of death are related to aspects of one's daily lifestyles [6]. Family members who take care of hospice patients tend to experience negative emotions associated with death, such as anxiety, pain, and fear of the afterlife [7]. According to a pervious study of grieving family members [8], more negative perceptions of death were associated with greater difficulty adjusting to life after the death of a family member. Therefore, in order to help family members taking care of hospice patients adjust to life after the patients' death and to support their psychological well-being, it is necessary to understand the family members' perceptions of death.

Health professionals in hospice care units can support patients and their family members to prepare for death with dignity and to reduce the shock that they may feel in panicinducing situations at the end of life by providing information about the situations and characteristics before and after death [9-11]. In fact, some studies have reported that families who prepared for death were less shocked by sadness than those who did not [8,9], which underscores the critical need to provide information about changes in the patients' condition, what the dying process is like, and what needs to be done during the dying process to prepare for death $[4,10]$. A lack of preparation for death including information and psychological support may lead family members to feel anxious and fearful due to the unpredictable condition of the patient and signs that indicate imminent death, and these experiences may result in developing negative perceptions of death [12]. Therefore, it is necessary to support family members of hospice patients as they prepare for the patient's death to ease anxiety and re-establish the meaning of life and perceptions of death. Moreover, through verbal and non-verbal communication expressing acceptance and empathy toward the pain and experiences of family members who are preparing to say good-bye to $\mathrm{pa}^{-}$ tients, comprehensive and holistic care should be implemented. Hospice care for patients in the terminal stage focuses on comprehensive pain and symptom management in preparation for death, rather than clinical treatment for recovery. Hospice nurses provide necessary resources and information for $\mathrm{pa}^{-}$ tients and their family members to prepare for the end of life and dignified death [10]. Death counseling can help patients and their family members overcome the fear associated with death and the dying process, resolve psychological trauma by promoting mutual forgiveness, and adjust to life after the patient's death $[13,14]$. Although some hospice institutions in South Korea provide professional death counseling, guidelines for systemic death counseling have rarely been developed and empirical evidence on the effect of death counseling is very limited [13]. Hospice care units provide various care programs, such as music and art therapy for patients and family members, but programs for supporting and helping patients and family members at the end of life are relatively few.

Existing studies have reported various factors associated with perceptions of death and anxiety among family members of hospice patients, but few studies have examined the effects of death counseling involving therapeutic communication with family members of hospice patients at the end of life. Therefore, this study aimed to investigate the effect of death counseling provided by hospice nurses for family members caring for hospice patients on the family members' perceptions, preparedness, and anxiety regarding death in order to provide preliminary data that can be used to deliver high-quality hospice care.

\section{Purpose}

The aim of this study was to provide preliminary evidence on 
the effect of death counseling for family caregivers of hospice patients on their perceptions, preparedness, and anxiety regarding death.

\section{METHODS}

\section{Study design}

This single-group pre-post design study was conducted to understand the effect of death counseling delivered to family caregivers of hospice patients. Due to the ethical difficulty in creating a comparison group, considering the circumstances of hospice patients who are at the end of life, the study was designed with a single group.

\section{Study participants}

The study participants were family members who were the primary caregivers for patients who had been hospitalized for at least 3 days and scored less than $40 \%$ on the Palliative Performance Scale (PPS) in a hospice and palliative care unit in a teaching hospital in J city, North Jeolla Province and who voluntarily chose to participate in death counseling.

The PPS is an indicator that assesses the level of activity, dis- ease, self-care capacity, oral ingestion, and consciousness of terminal patients [15]. The PPS demonstrates a high correlation with patients' prognosis, and a PPS of $40 \%$ indicates bedridden status, severe disease, dependence on a caregiver due to difficulty in self-care, reduced oral ingestion, and lethargic or normal consciousness. This study defined a PPS lower than $40 \%$ as predictive of death [15].

The sample size was calculated using $G^{*}$ Power version 3.1.9. For the paired t-test with an effect size of 0.5 , a significance level $(\alpha)$ of 0.05 , and power of 0.80 , a minimum of 34 par- $^{-}$ ticipants was necessary. Considering a $10 \%$ drop-out rate, data were collected from 37 participants.

\section{Death counseling}

Death counseling took place in a counseling room within the hospice and palliative care unit that had a quiet and soft atmosphere and a sound-proof wall for the comfort of participants. Death counseling was conducted one-on-one, in person, and for 60 minutes according to the communication method based on the SPIKES model [14], a therapeutic communication method, with topics of before death, the dying process, after death, and grief (Figure 1). In hospice and palliative care, psychotherapy or a counseling intervention for

\begin{tabular}{|c|c|c|c|c|}
\hline Step & Contents & Verbal communication & $\begin{array}{c}\text { Non-verbal } \\
\text { communication }\end{array}$ & $\begin{array}{l}\text { Time } \\
\text { (min) }\end{array}$ \\
\hline & & $\downarrow$ & & \\
\hline \multirow[t]{2}{*}{ Setting } & $\begin{array}{l}\text { Interview } \\
\text { preparation and } \\
\text { invitation }\end{array}$ & $\begin{array}{l}\text { I want to take time to } \\
\text { provide the best care. } \\
\text { Are you okay? }\end{array}$ & $\begin{array}{l}\text { Match the } \\
\text { eye level }\end{array}$ & 5 \\
\hline & \multicolumn{4}{|c|}{$\downarrow$} \\
\hline \multirow[t]{2}{*}{ Perception } & $\begin{array}{l}\text { Listening about } \\
\text { the past life }\end{array}$ & $\begin{array}{l}\text { Can you tell me what your } \\
\text { family has experienced } \\
\text { and understands? }\end{array}$ & $\begin{array}{l}\text { Nod, simple voice, } \\
\text { proper reaction }\end{array}$ & 10 \\
\hline & \multicolumn{4}{|c|}{$\downarrow$} \\
\hline \multirow[t]{2}{*}{ Invitation } & $\begin{array}{l}\text { Discussing how } \\
\text { to communicate } \\
\text { information }\end{array}$ & $\begin{array}{c}\text { Can I explain } \\
\text { what can happen? }\end{array}$ & Sympathetic face & 5 \\
\hline & \multicolumn{4}{|c|}{$\downarrow$} \\
\hline \multirow[t]{2}{*}{ Knowledge } & $\begin{array}{l}\text { - Before death } \\
\text { - The dying process } \\
\text { - Shortly after death } \\
\text { - Bereavement }\end{array}$ & $\begin{array}{l}\text { Can I help you prepare for a } \\
\text { dignified death just as you prepare } \\
\text { things when your child is born? } \\
\text { (Later stage of death) }\end{array}$ & $\begin{array}{l}\text { Tone of the voice, } \\
\text { voice speed control, } \\
\text { soft eye contact }\end{array}$ & 30 \\
\hline & \multicolumn{4}{|c|}{$\downarrow$} \\
\hline \multirow[t]{2}{*}{ Emotion } & $\begin{array}{l}\text { Responding to } \\
\text { emotions }\end{array}$ & $\begin{array}{l}\text { Yes. It's very normal } \\
\text { to feel this way }\end{array}$ & Silence, contact & 5 \\
\hline & \multicolumn{4}{|c|}{$\downarrow$} \\
\hline Strategy & $\begin{array}{l}\text { Summarizing } \\
\text { and organizing } \\
\text { conversations }\end{array}$ & $\begin{array}{c}\text { I will remember what } \\
\text { your family wants. } \\
\text { We will do our best to the end }\end{array}$ & Expression, posture & 5 \\
\hline
\end{tabular}

Figure 1. Process of death counseling based on the SPIKE model. 
patients or their family members takes approximately 50 minutes [16]. Prior experimental studies on the effects of education, music, or laughter therapy in South Korea [17-19] found that attitudes toward caring hospice patients became more positive after one session of an educational program providing information about hospice [17], anxiety was reduced after one session of music therapy (50 minutes) [18], and anxiety was reduced after one session of laughter therapy (60 minutes) [19]. Based on the evidence that a 60 -minute program is enough to be effective [17-19], and considering the limited time left for hospice patients, counseling was planned as one 60-minute session.

In the initial setting stage, the counseling room was organized to create a good atmosphere, and the conversation started with adjusting to the participants' eye level and reading the prompt "In order to provide the best care for you, I would like to have a conversation about your current status and future plans with you. Would that be okay?"

In the second stage ("perception"), the question "Can you describe the patient's and family members' lives from when the patient was diagnosed to now?" was asked to understand the degree to which the participant was aware of the patient's status and preparation for death.

In the third stage ("invitation"), the participant was reminded of the purpose and theme of the counseling session using the question "Would it be helpful if I explained what can happen when the patient's status deteriorates?", and information about the process and preparation for death was discussed during the main death counseling.

In the fourth stage ("knowledge"), information about the situational characteristics of death was provided. The content of death counseling aimed at information provision was based on hospice counseling [20] and was reviewed by three health professionals (i.e., one doctor and two advanced practice nurses) in hospice and palliative care. The content was categorized into before death, the dying process, after death, and the grieving period. The information about the period of before death included physical and emotional changes that signal imminent death, the care desired by family members, advance medical directives, and wills. The content on the dying process included responding to common symptoms during the dying process such as difficulty breathing, delirium, and pain, and saying the last good-byes with family members. The information about the period after death contained body cleaning and religious ceremonies. Lastly, information about the psychological characteristics of grieving, the process of overcoming sadness, and grief support groups for family members were provided. This stage began with the question "We hope you do not encounter these problems, but we are worried that the situation can deteriorate. Just like parents prepare for the arrival of their child by buying baby products and setting up the environment because they love the baby even before the baby' s birth, wouldn't it be nice to prepare for the death of the patient as you love the patient so much?", aimed to connect with the participant.

In the fifth stage ("emotion"), support for the sufficient expression of emotions such as regret and sadness was given, and conversations included expression of sympathy such as "It's perfectly natural to feel that way."

In the final stage ("strategy"), the discussions that occurred during the counseling session were summarized, and a plan to prepare for and overcome situations after the patients' death was made. The counseling closed with expressions of support and empathy such as "I will keep in mind what your family wants."

According to the guideline for therapeutic communication, persistent support was provided throughout the counseling session by observing participants' reactions, using easyto-understand vocabulary, and maintaining an attitude that reflected active listening and empathy. Constantly telling participants to calm down or giving unnecessary compliments, criticism, or advice was avoided, and if the participants wanted to stop the session due to an emotional reaction or discomfort, the session was stopped immediately.

\section{Study tools}

\section{1) Participants' characteristics}

The characteristics of the family caregivers of hospice patients were recorded using seven items on age, sex, relationship with the patient, religion, whether they received medical benefits, whether the patient was terminal, and the number of caregivers for the patient. The characteristics of hospice patients were recorded using five items on the duration in hospice, whether they were terminal, main symptoms, and whether they had completed advance directives. 


\section{2) Perceptions of death}

Perceptions of death were measured with the Measure of Concept of a Good Death, which was developed by Schwartz et al. [21] and translated into Korean by Jeong [11]. This scale consists of 17 items measured on a 4-point scale, categorized into three sub-scales of closeness (9 items), sense of control (3 items), and clinical symptoms (5 items). Each item is answered on a scale of "not important at all" (1 point), "not important" (2 points), "important" (3 points), and "very important" (4 points). The total score ranges from 17 to 68 , with higher scores indicating greater awareness of a good death. Cronbach' s $\alpha$ of the scale in the original paper was 0.87 , and it was 0.78 in the current study.

\section{3) Anxiety}

Anxiety was measured with the State-Trait Anxiety Inventory developed by Spielberger et al. [22] and translated by Kim and Shin [23]. This tool consists of 20 items, including 10 positively worded items and 10 negatively worded items, measured on a 4-point scale from "not at all" (1 point) to "somewhat" ( 2 points), "average" (3 points), and "very much" (4 points). The positively worded items are reverse-coded and added to the total score of the negatively worded items. The score ranges from 20 to 80, with higher score indicating higher levels of anxiety. Cronbach's $\alpha$ of the tool at the time of development was 0.87 , and was 0.88 in this study.

\section{4) Preparedness for death}

Preparedness for death was measured with a scale developed for this study. One professor in nursing and two advanced practice nurses in hospice and palliative care with more than 10 years of clinical experience created 11 preliminary items based on the following resources: the Hospice Service Guide provided by the National Cancer Center [10], the guidelines regarding the conceptual basis and practice of hospice and palliative care presented in the "Death Education and Family Support" chapter of a textbook entitled Hospice and Palliative Care [24], and empirical evidence from several countries on hospice nursing care regarding the mental and practical preparations of family members of hospice patients for the patients' death. The item content validity index of the 11 preliminary items, as reviewed by a group of professionals composed of five nurses who had worked in hospice and palliative care units for more than 3 years, was greater than 0.80 , and the average scale-level content validity index/average was 0.99 .

Eleven items were finalized, including understanding of preparation for death (7 items) and practical preparation for death such as funeral preparations (4 items), measured on a 4-point scale from "not at all" (1 point), to "somewhat" (2 points), "agree" (3 points), and "strongly agree" (4 points). The score ranged from 11 to 44, with higher scores indicating greater preparedness for death. Cronbach's $\alpha$ of the tool was 0.87 . In order to additionally understand what was lacking regarding preparations for death, an open-ended question ("What help do you need in preparing for your family member's death?") was included.

\section{Data collection}

The goals and the entire protocol of this study received approval from the institutional review board of J university hospital (2019-06-011-003). This study was conducted from August 26 to November 14, 2019. Participants eligible to participate in this study were given full information about this study, including the aims and purposes of the study, steps and procedure for participation, benefits and potential risk of participation, and rights guaranteed to participants (i.e., that participants can discontinue or withdraw the participation whenever they want). A written consent form was obtained from participants who expressed an interest in voluntarily participating in the study. Before scheduling death counseling as an intervention, descriptive information of sociodemographic characteristics of participants (i.e., family caregivers) and patients, perceptions of death, anxiety related to death, and level of preparedness for death was assessed using a selfadministered questionnaire. Considering the potential emotional responses or physical fatigue after death counseling, the post-counseling survey on perceptions of death, anxiety, and level of preparedness for death was conducted the day after counseling.

\section{Statistical analysis}

The collected data were analyzed using SPSS for Windows version 23.0 (IBM Corp., Armonk, NY, USA). Participants' characteristics and perceptions, preparedness, and anxiety re- 
garding death were presented in terms of frequency, percentage, mean, and standard deviation.

Differences in perceptions, preparedness, and anxiety regarding death before and after death counseling were analyzed using the paired t-test. Answers to the open-ended question were analyzed using content analysis, which is based on grounded theory as a method for inductively deriving a theory from data. Similar responses were grouped together to create sub-categories, which were abstracted to higher categories. The frequency of each category was observed.

\section{RESULTS}

\section{Participants' characteristics}

The average age of the family caregivers of hospice patients

Table 1. General Characteristics of Family Caregivers and Hospice Patients ( $N=37$ ).

\begin{tabular}{|c|c|c|c|c|}
\hline \multicolumn{2}{|c|}{ Characteristics } & \multirow{2}{*}{$\begin{array}{r}\text { Categories } \\
<50\end{array}$} & \multirow{2}{*}{$\frac{n(\%)}{11(29.7)}$} & \multirow{2}{*}{$\begin{array}{l}\text { Mean } \pm \text { SD (range) } \\
60.30 \pm 12.53(38 \sim 82)\end{array}$} \\
\hline Family caregivers & Age (yr) & & & \\
\hline & & $50 \sim 59$ & $7(18.9)$ & \\
\hline & & $60 \sim 69$ & $7(18.9)$ & \\
\hline & & $\geq 70$ & $12(32.5)$ & \\
\hline & Gender & Male & $15(40.5)$ & \\
\hline & & Female & $22(59.5)$ & \\
\hline & Relationship & Spouse & $26(70.3)$ & \\
\hline & & Offspring & $10(27.0)$ & \\
\hline & & Others & $1(2.7)$ & \\
\hline & Religion & Yes & $25(67.6)$ & \\
\hline & & No & $12(32.4)$ & \\
\hline & Medical recipient & Yes & $2(5.4)$ & \\
\hline & & No & $35(94.6)$ & \\
\hline & Perception of life expectancy & Yes & $35(94.6)$ & \\
\hline & & No & $2(5.4)$ & \\
\hline & Number of family caregivers & 1 & $20(54.1)$ & \\
\hline & & 2 & $14(37.8)$ & \\
\hline & & 3 & $3(8.1)$ & \\
\hline \multirow[t]{18}{*}{ Hospice patients } & Duration of hospitalization (d) & $<14$ & $5(13.5)$ & $29.54 \pm 20.35$ (6 92) \\
\hline & & $14 \sim 27$ & $17(45.9)$ & \\
\hline & & $28 \sim 41$ & $6(16.2)$ & \\
\hline & & $\geq 42$ & $9(24.4)$ & \\
\hline & Awareness of terminal status & Yes & $25(67.6)$ & \\
\hline & & No & $12(32.4)$ & \\
\hline & Advance care plan & Yes & $35(94.6)$ & \\
\hline & & No & $2(5.4)$ & \\
\hline & Major symptom* & Pain & $34(25.5)$ & \\
\hline & & Dyspnea & $18(13.5)$ & \\
\hline & & Vomiting & $4(0.3)$ & \\
\hline & & Delirium & $21(15.7)$ & \\
\hline & & Fever & $16(12.0)$ & \\
\hline & & General weakness & $36(27.0)$ & \\
\hline & & Others & $4(0.3)$ & \\
\hline & PPS (\%) & 20 & $1(3.0)$ & $36.48 \pm 5.30$ \\
\hline & & 30 & $11(29.0)$ & \\
\hline & & 40 & $25(68.0)$ & \\
\hline
\end{tabular}

PPS: palliative performance scale.

*Multiple responses. 
was 60.30 years; $12(32.5 \%)$ were above the age of 70 , comprising the largest group, and seven (18.9\%) each were in the age groups 50 59 and 60 69. Twenty-two (59.5\%) were women, and in terms of the relationship with the patient, 26 (70.3\%) were spouses and 10 (18.9\%) were children. Most frequently, two people $(37.8 \%)$ helped to take care of the patient. Twenty-five (67.6\%) were religious, and 35 (94.6\%) recognized that the patient was terminal.

The length of the patient's stay in hospice was on average 29.54 days, ranging from 6 to 92 days. Almost half of the patients $(\mathrm{n}=17 ; 45.9 \%$ ) had been in hospice from 14 to 27 days. Twenty-five patients $(67.6 \%)$ recognized that they were terminal, and 35 patients (94.6\%) had completed an advance directive. The most common symptoms experienced by patients were lethargy $(n=36,27 \%)$ and pain $(n=34,25.5 \%)$. The average PPS was $36.48 \% ; 25$ patients had a PPS of $40 \%$ and 11 patients had a PPS of $30 \%$ (Table 1).

\section{Effects of death counseling}

The score for perceptions of death of a family member increased from 55.14 before death counseling to 58.30 after

Table 2. Differences in Perceptions, Anxiety, and Preparedness Regarding Death and Dying before and after Death Counseling ( $N=37)$.

\begin{tabular}{lcccrrr}
\hline \multirow{2}{*}{ Variable } & Pre-test & & Post-test & & \\
\cline { 2 - 2 } & Mean \pm SD & & Mean \pm SD & & P \\
\hline Perceptions of death & $55.14 \pm 5.09$ & & $58.30 \pm 4.04$ & -4.90 & $<0.001$ \\
Anxiety & $68.38 \pm 8.64$ & & $65.14 \pm 9.86$ & 3.72 & 0.001 \\
Preparedness for & $23.46 \pm 5.78$ & & $35.51 \pm 3.38$ & -16.23 & $<0.001$ \\
death & & & & & \\
\hline
\end{tabular}

counseling $(\mathrm{P}<0.001)$, and the score for anxiety decreased from 68.38 to $65.14(\mathrm{P}<0.001)$. The score for preparedness for death increased from 23.46 to $35.51(\mathrm{P}<0.001)$ (Table 2).

The help needed while preparing for the patient's death changed after counseling. The help that family members requested before death counseling was categorized into three categories. The first category was information about the symptoms of death $(n=20)$, which included symptoms that the patient will experience and specific ways to respond and care for those symptoms. The second category was information about life expectancy $(n=16)$, as family members reported needing help with knowing how long the patient would be likely to live and when to assemble family members. The third category was information about funeral preparation $(n=5)$.

After death counseling, the area that family members identified most as needing help with was support during the patient' $s$ death $(n=32)$. Family members asked for help in giving the patient a painless and comfortable death up to the very last moment. The second category was information about symptoms of death, and third category was psychological support to calm their minds (Table 3).

\section{DISCUSSION}

This study investigated the effect of death counseling provided to family caregivers of hospice patients on perceptions, preparedness, and anxiety regarding death with the major goal of building upon preliminary evidence for developing a comprehensive care program for hospice patients and their family members.

Table 3. Family Members' Statements Regarding Help Needed While Preparing for Death ( $N=37$ ).

\begin{tabular}{ll}
\hline \multicolumn{1}{c}{ Before death counseling } & \multicolumn{1}{c}{ After death counseling } \\
\hline Information on the symptoms of death $(n=20)$ & Support for the patient's death $(n=32)$ \\
- Symptoms in the future $(n=12)$ & - Comfortable dying without pain $(n=22)$ \\
- Coping with ongoing symptoms $(n=4)$ & - Attitude that medical staff do their best to the end $(n=10)$ \\
- What the family should do in the future $(n=3)$ & \\
- Patient care information $(n=1)$ & Information on death symptoms $(n=6)$ \\
Information about the expected transition $(n=16)$ & - Information about new symptoms $(n=4)$ \\
- Survival information for funeral preparation $(n=13)$ & - Information about ongoing symptoms $(n=2)$ \\
- Last time to greet family $(n=3)$ & Support for peace of mind $(n=2)$ \\
Information about funeral preparations $(n=5)$ & \\
- Funeral procedures $(n=4)$ & \\
- Funeral preparation $(n=1)$ & \\
\hline
\end{tabular}


The recipients of hospice and palliative care include patients and their family members; therefore, in order for the dying process to be meaningful for family members, it is necessary to provide family care based on an understanding of psychological and perceptual distress that family members may experience through preparing for and facing the death of their loved one [13]. Studies have been conducted among the family members of hospice patients, including one that reported the effects of providing information about pain management, physical care, nutrition care, and preparation for death in a small group setting [25] and another study that evaluated the effects of supportive education on pain management, stress, death management, and grief management [26]. These studies focused on educational interventions for providing information and there is little information on death counseling. Therefore, it is worthwhile that this study evaluated the effect of death counseling that incorporated therapeutic communication skills, which are not limited to the provision of information about the characteristics of each stage (before death, dying process, after death, and grief), but also encompass the emotional and psychological characteristics of the family member's relationship with the patient and personal life experiences.

The death counseling provided in this study had positive effects on perceptions, preparedness, and anxiety regarding death among the family members of hospice patients. The score for family members' perceptions of death increased from 55.14 to 58.30 after counseling, which was a higher score than those of 51.96 found among the main family caregivers of home nursing patients [27] and 52.13 reported among elderly cancer patients [28] that used the same scale. This trend might reflect the effects of psychological and spiritual care [9], which provides the opportunity to contemplate death and look back upon life and the relationships between the patient and family members, beyond the informational and physical care about the patient's disease status provided in hospice care units. This finding also indicates that for the comprehensive care that hospice and palliative care pursues, it is important to provide care that involves understanding characteristics such as perceptions of death among patients' family members and includes death counseling using therapeutic communication methods when death is near in order to improve family members' pessimistic perspectives on family members' death and to establish values about life and death.

In this study, anxiety levels of family members decreased from 68.38 before counseling to 65.14 after counseling. This finding is similar to those of previous studies $[25,26]$ reporting that educational programs including emotional support for family members of hospice patients reduced anxiety. The emotion stage in the SPIKES model applied for the current study involved strategies of accepting and protecting family members' responses through empathy, and helped to reduce anxiety associated with death (since the family members of hospice patients cannot experience the patients' death in advance) through empathy and emotional support from medical staff [14]. This underscores the importance of implementing a death counseling program that applies a more systematic therapeutic communication method to understand and empathize with the pain experienced by family members of patients at their end of life holistically.

The score for preparedness for death among the family members of hospice patients increased from 23.46 before counseling to 35.51 after counseling. This result confirms that death counseling is an intervention that goes beyond simply delivering information and increasing knowledge; instead, it explores the psychological pain of family members who share their lives with the patient, supports them with empathy and reflection to overcome, and helps them to say their last goodbye to the patient in a practical manner. Preparedness for death was measured using a developed tool based on empirical evidence regarding the socio-cultural context of family caregiving in South Korea by which family members play a major role in preparing for death and decision-making about funeral procedures [9,24]. In a previous study [28], preparing for death referred to practical preparations such as making a will, deciding on a final resting place, preparing a photo, and deciding the type of funeral.

In contrast, the tool used in the current study to assess the preparedness for death measured included content related to making medical decisions before the patient's death, meeting to grieve and say good-bye, and overcoming grief after death on top of practical preparations, which cover a broader range of psychological and spiritual characteristics regarding preparedness for death among family members of hospice patients. Therefore, it is expected that this tool can be used to promote 
quality improvement in hospice and palliative care services that implement comprehensive care. The content validity of the items used to measure preparedness for death was evaluated by an expert group, but further scientific evidence for expanding the use of this tool use to studies of the family members of hospice patients should be obtained by conducting systematic tests of the construct validity of the items in the future.

For a better understanding of the characteristics in the preparedness for the patient's death among the family members of hospice patients in detail, content analysis was conducted of the responses to the open-ended questions asking about what type of support family members needed in preparation for death. Before death counseling, the participants expressed a great demand for information about symptoms of death, whereas after death counseling, they expressed need for support in providing a comfortable death. This result is consistent with previous findings that the informational and educational needs of family members of hospice patients were the most unmet needs [4] and that family members who received education to prepare for death identified medical information provision as the most helpful [29]. The type of help needed by family members changed through death counseling. Family members wished for support so that patients could maintain human dignity and a sense of well-being until the very last moment of their lives.

Family members' burden of caregiving and emotional stress increase as the patient's death approaches, and family members feel fear regarding facing death, which they have not experienced before [30], so it is necessary to provide supportive nursing that goes beyond merely supplying information to calm their minds. It is important to provide family members of hospice patients opportunities to ask questions that enhance their understanding of patients' clinical characteristics when it comes time to prepare for death and to provide information repeatedly so that they can plan for future situations.

The death counseling delivered to family members of hospice patients in this study was a holistic care intervention that supported family members during the patient's dying process and promoted their security so that they could prepare for the patient's death well. Thus, it is necessary to formulate detailed and systematic characteristics for each stage of death counseling. Since this study only included family members of terminal cancer patients in a hospice and palliative care unit of one university hospital in J city, death counseling should be implemented for participants who are facing death in various environments other than a hospice and palliative care unit. Future studies should take into account sociodemographic characteristics and psychosocial characteristics, which can influence death counseling for the family members of hospice patients, and efforts should be made through further research to develop a practical protocol for hospice patients and their family members to prepare for death.

\section{CONFLICT OF INTEREST}

No potential conflict of interest relevant to this article was reported.

\section{ORCID}

Yeojung Jung, https://orcid.org/0000-0003-0257-4828

Hyun-E Yeom, https://orcid.org/0000-0001-6541-7526

Na-Ri Lee, https://orcid.org/0000-0002-6236-9319

\section{AUTHOR'S CONTRIBUTIONS}

Conceptualization: YJ, HEY, NRL. Data collection: YJ, NRL. Formal analysis: YJ, HEY. Supervision: HEY. Validation: YJ, HEY, NRL. Writing - original draft: YJ, HEY. Writing - review \& editing: HEY.

\section{SUPPLEMENTARY MATERIALS}

Supplementary materials can be found via https://doi. org/10.14475/jhpc.2021.24.1.46.

https://doi.org/10.14475/jhpc.2021.24.1.46 


\section{REFERENCES}

1. National Cancer Center; National Hospice Center [Internet]. Current situation and statistics. [cited 2020 Jun 1] Available from: https://hospice.cancer.go.kr/pain/stat.do?menu_no=634\&brd_mgrno=.

2. Ferrell B, Coyle N, Paice JA. Oxford textbook of palliative nursing. New York:Oxford University Press;2015. p.109.

3. National Hospice Center. Evaluation results of the bereavement family satisfaction survey in 2018, 2019.

4. Lee JH. Unmet needs and caregiver burden among the family caregivers of hospice patients [master's thesis]. Seoul: Ewha Womans Univ.; 2016. Korean.

5. Park B, Kim SY, Shin JY, Sanson-Fisher RW, Shin DW, Cho J, et al. Suicidal ideation and suicide attempts in anxious or depressed family caregivers of patients with cancer: a nationwide survey in Korea. PLoS One 2013;8:e60230.

6. Lee JY, Rhee KO. A study on older adult's recognition of the death. Journal of the Korean Gerontological Society 2004;24:193-215.

7. Choi YS, Kim DS. Concepts associated with death, fear and fear overcoming methods held by patients with cancer in terminal stage and their families in hospice [master's thesis]. Daejon: Chungnam National Univ.; 2012. Korean.

8. Schulz R, Boerner K, Klinger J, Rosen J. Preparedness for death and adjustment to bereavement among caregivers of recently placed nursing home residents. J Palliat Care. 2015;18:127-33.

9. Heo HJ, Kwon YC. The effect of family resilience, social support and death recognition on quality of death on the adaptation of bereavement family. Journal of Digital Convergence 2019;17:271-80.

10. National Cancer Center; National Hospice Center [Internet]. Hospice service guide. 4th ed. Goyang: National Cancer Center; National Hospice Center; 2019. [cited 2020 Jun 1] Available from: https://hospice.cancer.go.kr/pain/archivesView.do? brd_no=92096.

11. Jeong HS. Recognition towards good death among physicians and nurses in an area [master's thesis]. Busan: Catholic Univ.; 2010. Korean.

12. Cho YH. Attitude of hospice patient's family to ward death and hospice [master's thesis]. Daegu: Kyungpook National Univ.; 2009. Korean.

13. Korean Hospice \& Palliative Nurses Association. Hospice palliative nursing. Seoul:Hyunmoon;2015.

14. Kaplan M. SPIKES: a framework for breaking bad news to patients with cancer. Clin J Oncol Nurs 2010;14:514-6.

15. Lau F, Maida V, Downing M, Lesperance M, Karlson N, Kuziemsky C. Use of the Palliative Performance Scale (PPS) for end-of-life prognostication in a palliative medicine consultation service. J Pain Symptom Manage 2009;37:965-72.

16. Gramm J, Trachsel M, Berthold D. Psychotherapeutic work in palliative care. Verhaltenstherapie [Internet]. 2020 [cited 2020 Jun 1]. Available from: https://www.karger.com/Article/FullText/505120\#.

17. Roh SY. Changes in family caregivers attitude towards hospice care after the provision of information on hospice and palliative care [master' s thesis]. Daejon: Chungnam National Univ.; 2017. Korean.

18. Kim SY, Kim YS. The effects of listening-centered and singing-centered single-session music therapy intervention on pain, anxiety, and depression of the gynecologic cancer patients receiving chemotherapy. KJMT 2010;12:1-18.

19. Han HJ, Park AR, Kim HS, Moon HK, Park YH. The effects of laughter therapy on stress responses in patients with preoperative breast cancer. J Korean Oncol Nurs 2011;11:93-100.

20. Parkes CM, Relf M, Couldrick A. Counselling in terminal care and bereavement. Leicester:British Psychological Society;1996.

21. Schwartz CE, Mazor K, Rogers J, Ma Y, Reed G. Validation of a new measure of concept of a good death. J Pallative Med 2003;6:575-84.

22. Spielberger CD, Gorsuch RL, Lushene RE. Manual for the state-trait anxiety inventory. Palo Alto, CA:Consulting Psychologists Press;1970.

23. Kim JT, Shin DG. A Study Based on the Standardization of the STAl for Korea. The New Medical Journal 1978;21:69-75.

24. Longaway D. Death education and family support. In: Forman WB. Hospice and palliative care : concepts and practice. 2nd ed. Sudbury, Mass: Jones and Bartlett;2003. p.229-40.

25. Choi JR. The effects of an informational support program on social support, depression, and anxiety for family caregivers of patients with terminal cancer [master's thesis]. Gyeongsan: Catholic Univ.; 2009. Korean.

26. Lee TY. Effects of supportive education program for hospice patients' families [master's thesis]. Daegu: Keimyung Univ.; 2013. Korean.

27. Ku SM. Perception on home care hospice and well dying among family caregivers of patients receiving home care [master's thesis]. Seoul: Hanyang Univ.; 2017. Korean.

28. Kim MS, Ha CK, Kim HS. A study on life satisfaction, the view of the afterlife and readiness for death. KJFW 2011;16:111-36.

29. Jeong IS. A study of factors influencing grief among the bereaved family of the hospice patients [master's thesis]. Seoul: Ewha Womans Univ.; 2008. Korean.

30. Lee JH, Park HK, Hwang IC, Kim HM, Kim YS, Lee YJ, et al. Factor associated with care burden among family caregivers of terminally ill cancer patients. Korean J Hosp Palliat Care 2016;19:61-9. 